\title{
RECORDING PAEDIATRIC CANCER STAGE IN POPULATION-BASED CANCER REGISTRIES: THE TORONTO CONSENSUS PRINCIPLES AND GUIDELINES
}

Sumit Gupta, PhD, ${ }^{1,2}$ Joanne F. Aitken, PhD ${ }^{3}$ Ute Bartels, MD, ${ }^{1,2}$ James Brierley, MBBS, ${ }^{4}$ Mae Dolendo, MD,${ }^{5}$ Paola Friedrich, MD, ${ }^{6}$ Soad Fuentes-Alabi, MD, ${ }^{7}$ Claudia P. Garrido, MD ${ }^{8}$ Gemma Gatta, MD,${ }^{9}$ Mary Gospodarowicz, MD, ${ }^{4}$ Thomas Gross, $\mathrm{PhD},{ }^{10}$ Scott C. Howard, MD,${ }^{11}$ Elizabeth Molyneux, FRCPCH, ${ }^{12}$ Florencia Moreno, MD, ${ }^{13}$ Jason D. Pole, PhD,${ }^{14}$ Kathy Pritchard-Jones, PhD,${ }^{15}$ Oscar Ramirez, MD, ${ }^{16}$ Lynn

A.G. Ries, MS, ${ }^{17}$ Carlos Rodriguez-Galindo, $\mathrm{MD}^{6}$ Hee Young Shin, $\mathrm{PhD},{ }^{18}$ Eva Steliarova-Foucher, PhD, ${ }^{19}$ Lillian Sung, $\mathrm{PhD},{ }^{1,2}$ Eddy Supriyadi, PhD,${ }^{20}$ Rajaraman Swaminathan, $\mathrm{PhD},{ }^{21}$ Julie Torode, $\mathrm{PhD},{ }^{22}$ Tushar Vora, $\mathrm{MD}^{23}$, Tezer Kutluk, $\mathrm{PhD},{ }^{22}$ and A. Lindsay Frazier, MD $^{6}$

${ }^{1}$ Division of Haematology/Oncology, Hospital for Sick Children, 555 University Avenue, Toronto, Canada, M5G 1 X8

${ }^{2}$ Department of Paediatrics, Faculty of Medicine, University of Toronto, 1 King's College Circle, Toronto, Canada, M5S 1A8

${ }^{3}$ Cancer Council Queensland, 553 Gregory Terrace, Fortitude Valley, Brisbane, Australia, 4006

${ }^{4}$ Department of Radiation Oncology, Princess Margaret Hospital, 610 University Avenue, Toronto, Canada, M5G 2M9

${ }_{5}^{5}$ Southern Philippines Medical Center, JP Laurel St., Bajada, Davao City, Philippines, 8000

${ }^{6}$ Dana-Farber/Boston Children's Cancer and Blood Disorders Center, 450 Brookline Avenue, Boston, USA 02215

${ }^{7}$ Hospital Nacional de Ninos Benjamin Bloom, San Salvador, El Salvador.

${ }^{8}$ Unidad Nacional de Oncologia Pediatrica, 9a. Ave. 8-00 Zona 11, Guatemala City, Guatemala, 01011

${ }^{9}$ Evaluative Epidemiology Unit, Fondazione IRCSS Instituto Nazionale dei Tumori, via Venezian 1, 20133 Milan, Italy

${ }^{10}$ Center for Global Health, National Cancer Institute, 9609 Medical Center Drive, Bethesda, USA, 20892

${ }^{11}$ University of Memphis, 3720 Alumni Avenue, Memphis, USA, 38152

${ }^{12}$ College of Medicine, Box 360, Blantyre 3, Malawi

${ }^{13}$ Argentinian Oncopediatric Registry (ROHA), National Cancer Institute, Av. Julio A Roca 781, CF, Buenos Aires, Argentina

${ }^{14}$ Pediatric Oncology Group of Ontario, 480 University Ave, Suite 1014, Toronto, Canada, M5G 1V2

${ }^{15}$ Institute of Child Health, University College London, 30 Guilford Street, London, UK, WC1N 1EH

${ }^{16}$ Registro Poblacional de Cancer de Cali, Universidad del Valle, Calle 4B \# 36-00, Edificio 116, Oficina 4009, Cali, Valle, Colombia

${ }^{17}$ SEER Program, National Cancer Institute (contractor), 9609 Medical Center Drive Bethesda, USA, 20892 
${ }^{18}$ Department of Pediatrics, Cancer Research Institute, Seoul National University College of Medicine, 103 Daehakro, Seoul, Korea, 03080

${ }^{19}$ Section of Cancer Surveillance, International Agency for Research on Cancer, 150 course Albert Thomas, Lyon, France, 69372

${ }^{20}$ Pediatric Hematology Oncology Division, Department of Pediatrics, Dr. Sardjito

Hospital, Gadjah Mada University, Jl. Kesehatan No. 1, Yogyakarta, Indonesia, 55281

${ }^{21}$ Epidemiology, Biostatistics and Cancer Registry, Cancer Institute (WIA), 38 Sardar

Patel Road, Chennai, India, 600036

${ }^{22}$ Union for International Cancer Control (UICC), 62 route de Frontenex, 1207 Geneva, Switzerland

${ }^{23}$ Tata Memorial Hospital, Dr. E. Borges Road, Parel, Mumbai, India, 400012.

Corresponding author: Dr. Sumit Gupta

Division of Haematology/Oncology

Hospital for Sick Children

555 University Avenue

Toronto, Ontario, Canada, M5G 1X8

T: 1-416-813-7654 x201681

E: sumit.gupta@sickkids.ca 


\begin{abstract}
Population-based cancer registries (PBCRs) generate estimates of incidence and survival that are essential for cancer surveillance, research, and cancer control strategies. Though cancer stage data allow meaningful assessments of changes in cancer incidence and outcomes, stage is not collected by most PBCRs. The principal method of staging adult cancers is the tumor, node, metastasis (TNM) classification. Paediatric cancer staging criteria vary by diagnosis, have evolved over time, and sometimes vary by cooperative trial group. Consistency in collection of staging data has therefore been challenging for PBCRs. We assembled key experts and stakeholders (oncologists, cancer registrars, epidemiologists) and utilized a modified-Delphi approach to establish principles guiding paediatric cancer stage collection. Using these principles, recommendations were made on which staging systems should be adopted by PBCRs for the major childhood cancers, including adaptations for low-income countries. Wide adoption of these Toronto Guidelines among registries will facilitate international comparative incidence and outcome studies.
\end{abstract}




\section{INTRODUCTION AND RATIONALE}

Population-based cancer registries are a unique resource for both cancer researchers and policymakers. ${ }^{1}$ Registry data have been used for disease surveillance and to derive population-based estimates of incidence, prevalence, and outcome in both adults and children.-5 The results of these investigations have been used in turn to plan and evaluate national cancer control strategies. ${ }^{13,6,7}$ Cancer stage is a core concept in oncology, providing a "common nomenclature on which to base cancer management, research and information exchange". ${ }^{8,9}$ Accurate stage data are crucial when comparing cancer outcomes between groups or over time. Despite this, many population-based cancer registries either do not collect stage data at all or, among paediatric patients, collect stage according to adult TNM staging. The "TNM" classification developed by the Union for International Cancer Control (UICC) is used to classify and code stage in many adult malignancies, but is not applicable to most paediatric cancers. ${ }^{8}$

Because of their heterogeneity and rarity, childhood cancers already represent a particular data management challenge for registries. ${ }^{10}$ Pertaining to paediatric cancer stage, most childhood malignancies are staged according to disease-specific staging systems that often differ between countries or clinical trial organizations. ${ }^{11}$ The utility of populationbased registries to childhood cancer research and policy is therefore limited by both the general lack of cancer stage data, the inadequacy of adult staging systems in reflecting extent of disease in children, and the use of multiple paediatric staging systems for the same malignancy. Finally, cancer registries in low- and middle-income countries 
(LMICs) face additional challenges given the unavailability or unaffordability of advanced imaging.

Our primary objectives were: 1) To identify the key principles that should guide the collection of childhood cancer stage by population-based cancer registries, and based upon these principles, 2) to recommend which staging system(s) should be used by cancer registries for 18 major childhood malignancies that can be applied by registry staff using available records, and that are sufficiently detailed for the purposes of analysis and interpretation of population cancer data, while respecting different capacities and resource levels. The resultant "Toronto Paediatric Cancer Stage Guidelines" have subsequently been endorsed by the UICC TNM Prognostic Factors Project. Our recommendations are not intended to replace staging systems in clinical use.

\section{METHODS}

\section{MODIFIED DELPHI PROCESS}

We assembled a panel of international experts and advocacy stakeholders, and undertook a modified-Delphi approach to consensus building. ${ }^{12,13}$ Invited experts represented diverse content expertise (e.g. clinicians and epidemiologists), geography, and resource settings in order to ensure the most generalizable and feasible recommendations. ${ }^{13}$ Representatives from selected cancer registries or registry associations were also invited. Invitees could nominate additional panelists.

Two Delphi rounds were conducted by email survey in order to identify guiding principles relevant to the collection of paediatric cancer stage in population-based registries. A search of Ovid Medline revealed only studies pertaining to specific 
malignancy cohorts and no articles were identified that provided principles for choosing one staging system over another. The consensus workshop leaders (SG, LF) therefore generated a list of candidate principles informed by the principles that have been endorsed for the collection of cancer stage in adult malignancies by the UICC TNM Prognostic Factors Project and through interviews with two experts in cancer registration (OR, LR), one from a HIC and one from a LMIC. $^{8}$ In round one, panelists were asked to rate each principle on a 5-point Likert scale (1=strongly agree, $2=$ agree, $3=$ neither agree nor disagree, $4=$ disagree, $5=$ strongly disagree). ${ }^{13}$ Panelists were also asked to provide comments on each principle, and to suggest additional principles for inclusion. In accordance with recently published guidelines, consensus was defined as $\geq 75 \%$ of respondents either agreeing or strongly agreeing with a principle, (median score $\leq 2) .{ }^{13}$ Any principle with which $\geq 75 \%$ respondents disagreed or strongly disagreed was eliminated.

Next, the consensus workshop leaders reviewed and revised any principles that had not achieved consensus, but had not been eliminated in round one. Based on round one feedback, several entirely new principles were also developed. In round two, panelists were asked to once again rate the revised or added principles, and were provided with their own previous rating from round 1, ratings distribution, and representative comments from the group. Responses were kept anonymous. Copies of both questionnaires can be seen in the supplemental material.

A one-day in-person meeting was then held for all panelists in Toronto, Canada (October $\left.19^{\text {th }}, 2014\right)$. The group reviewed each approved principle for content and phrasing. Those principles not achieving consensus were further discussed in detail and were either 
revised and accepted, or rejected. Finally, the entire set of principles achieving consensus was re-reviewed in order to minimize redundancy.

Panelists then broke into three working groups (WGs): hematologic malignancies, solid tumours, and neuro-oncology. Each WG comprised of epidemiologists, cancer registrars and paediatric oncologists with appropriate malignancy expertise. Groups were tasked with endorsing a staging system for use by population-based cancer registries using the set of principles that had achieved consensus as a guide. WGs were provided a list of the most common paediatric staging systems for each malignancy, but were also free to suggest alternatives. Each WG then presented their recommendations to the reassembled group, and after incorporating suggestions and refinements from the group, a final recommendation was made. Finally, panelists discussed strategies for disseminating the group's recommendations, anticipated challenges to adoption, and ways of overcoming these challenges.

\section{RESULTS}

\section{PANELISTS AND RESPONSE RATES}

Through an iterative process, two workshop leaders (SG, LF) ultimately identified 28 panelists who either had expertise in paediatric oncology $(n=20 ; 71.4 \%)$, epidemiology $(\mathrm{n}=14 ; 50 \cdot 0 \%)$, cancer registration $(\mathrm{n}=13 ; 46 \cdot 4 \%)$, or represented a key stakeholder such as the Union for the International Control of Cancer (UICC), International Agency for Research on Cancer (IARC), National Cancer Institute (NCI), or Surveillance, Epidemiology, and End Results (SEER) Program (Table 1). The 26 experts (92.9\%) who accepted the invitation to participate represented 17 countries and 6 continents; 10 
(35.7\%) panelists were from an LMIC. Twenty-five of the 26 experts (96.2\%) returned responses to the round one survey. All 25 subsequently returned responses to the round two survey. All $26(100 \%)$ participating individuals, plus the 2 workshop leaders, were present for the face-to-face meeting.

In round one, 18 principles were proposed; 13 achieved consensus and one was

eliminated (Supplemental Table 1). The four remaining original principles were modified according to round one comments and included in the round two surveys along with one new principle. Of these five second round principles three achieved consensus while two did not (Supplemental Table 2). During the consensus workshop, five principles that had achieved consensus were modified to improve phrasing without altering content. Subsequently, two principles referring to staging systems in low- and middle-income country (LMIC) settings were combined, as were two principles relating to uniformly collecting stage across registries, resulting in a total of 14 core principles. These principles, both those included and eliminated, are discussed in more detail below.

\section{PRINCIPLES OF PAEDIATRIC STAGE COLLECTION}

Principles guiding collection of paediatric stage data were grouped into 4 categories: rationale for collection, relationship to adult cancer staging, specificities of paediatric staging systems, and adaptation to resource-limited settings (Table 2).

Panelists overwhelmingly endorsed the importance of collecting stage for cases of paediatric cancer in population-based registries (principle 1). Information on stage allows researchers and policymakers to appropriately describe and risk stratify groups of patients when comparing outcomes between populations or trends over time (principle 
2) ${ }^{1,3,6,7}$ While not applicable to all childhood cancers or all healthcare settings, a metric of the success of public health efforts targeting early diagnosis in paediatric cancer patients is a downward shift in the distribution of stage at diagnosis (principle 3). ${ }^{14,15}$ Paediatric cancer-specific staging systems should be used for malignancies occurring principally in childhood (principle 4). In contrast, for malignancies common to both paediatric and adult populations (e.g. Hodgkin lymphoma, testicular cancer), the staging system commonly in use for adults should generally be recommended (principle 5). However, when a general TNM classification system developed for application in adult populations would not have the same prognostic value in younger patients, paediatric staging systems that more accurately reflect prognosis should be used (principle 6). Panelists noted that paediatric age ranges are defined differently across jurisdictions. ${ }^{4,5}$ We chose not to define an upper age limit for our staging recommendations, as this may vary between malignancies. For example, paediatric staging may be appropriate even in adults with neuroblastoma. ${ }^{16}$

Paediatric stage should reflect the anatomic extent of disease (principle 7) ${ }^{8}$, as distinct from "risk of recurrence". For instance, $M Y C N$ amplification is a critical prognostic feature in neuroblastoma associated with risk of recurrence, but is not a measure of "stage" or extent of disease. Non-stage prognostic features may also be collected by registries, but should not to be confused with "stage". Stage data should remain as simple as possible (principle 8) and follow internationally accepted classifications whenever possible in order to maintain comparability (principle 9). Both clinical staging (i.e. staging at the time of initial diagnosis - principle 10) and pathologic staging (i.e. staging at the time of surgery/resection - principle 11) hold 
importance. While the latter may allow for more accurate determination of disease extent through surgical pathology, it may underestimate the initial extent of disease if neoadjuvant therapy has been administered. Indeed, in particular paediatric malignancies, cooperative groups have differed on whether staging before or after neoadjuvant therapy is the most relevant for deciding upon the full course of treatment. ${ }^{17}$ The TNM system has developed "prefix modifiers" to address this issue. For instance, the "y" modifier, indicates that a patient's stage was assessed after the receipt of neoadjuvant therapy. ${ }^{18}$ Comparability between registries and regions is challenging in the face of several potential barriers. First, registries vary widely in terms of their human, infrastructural and financial resources. This is of significant concern in LMICs. In 2006, only 8\% of Asians and 11\% of Sub-Saharan Africans were covered by population-based cancer registries; when only high-quality registry data are considered, these rates were $4 \%$ and $1 \%$, respectively. ${ }^{19}$ This concern is however not restricted to LMICs; high-income country (HIC) registries also face increasing funding constraints. ${ }^{6}$ Second, registries vary in their ability to access primary data sources and in data quality. In many jurisdictions, paediatric cancer cases are identified through ongoing submission of pathology reports, hospital discharge abstracts and death certificates. ${ }^{4,20}$ By contrast, some jurisdictions have established specialized paediatric registries that benefit from a direct access to clinical records located at each site. ${ }^{21-23}$ These models result in a differential ability to access detailed stage data. Thus, while comparability between cancer registries is a key goal, ${ }^{24,25}$ a "one size fits all" approach to the recording of paediatric cancer staging was also deemed impractical. 
In order to balance these two opposing concerns, panelists endorsed a "tiered" approach to paediatric cancer staging (principle 12). In this tiered approach, lower tier staging systems are more basic and thus should be feasible for even resource-limited cancer registries to adopt. Higher-tier staging systems are more detailed and comprise a number of levels that can be collapsed down into those of the lower-tier systems, thus retaining comparability across registries. Indeed, highly resourced paediatric cancer registries may choose to develop "Tier 3" staging systems based on further subdividing Tier 2 categories in ways that continue to have prognostic import (e.g. site of metastases in malignant bone tumours, distinguishing CNS from bone marrow involvement in NHL). Comprehensive and valid Tier 1 stage data is preferable to incomplete Tier 2 data of unknown quality, and would still represent a major improvement from the current situation in many jurisdictions.

The panel failed to reach consensus on one principle during the face-to-face meeting, though it engendered significant discussion:

"Ideally, cancer registries should collect the methods of evaluation by which stage was determined in order to assess the adequacy of staging (e.g. Chest X-ray vs. CT scan for lung metastases)."

Stage is, in part, a reflection of the diagnostic modalities employed to ascertain it. Access to these modalities will vary widely between jurisdictions. For example, the staging workup for Burkitt lymphoma may range from clinical exam $+/$ - ultrasound in resourcelimited centres to combined CT/PET scans in many HIC centres. ${ }^{26,27}$ Children identified as having high-stage disease in these two settings may not be comparable; knowing which diagnostic modalities were utilized would allow assessment of staging adequacy 
when attempting cross-registry comparisons. Such data would also allow for changes in stage distribution to be identified as diagnostic capabilities improved. ${ }^{28}$ The concept of collecting data on the "validity" of stage was compared to the accepted concept of collecting the means of diagnosis (clinical, histological, etc) via a "certainty" or c-factor, already included as a concept of cancer registration..$^{29}$ Despite strong consensus on the utility of such information, panelists also noted the difficulty in collecting this data and the significant resources required. Although concerns over practicality prevented full group endorsement as a core principle, there was enthusiasm for pilot studies to determine the feasibility of collecting stage evaluation methods and whether the "cfactor" concept could be applied to cancer stage data.

\section{ENDORSING STAGING SYSTEMS FOR SPECIFIC MALIGNANCIES}

Panelists attempted to balance what staging information would ideally be recorded with the practical implications of obtaining such information. WGs were encouraged to endorse malignancy-specific "tiered"-staging systems when appropriate in order to help to strike this balance.

The recommendations for the collection of stage for the major childhood cancers are shown in Table 3 and discussed below. WGs noted that tumour stage is just one component of prognostic risk classification. While we restricted the purview of this meeting to stage, or extent of disease, other prognosticators could be considered for collection by registries with adequate resources and data access [e.g. cytogenetics in acute leukemia, $M Y C N$ status in neuroblastoma, molecular or epigenetic characterizations in brain tumours, International Germ Cell Consensus Classification (IGCCC) for 
metastatic germ cell tumours, extent of surgical resection in central nervous system tumours].

\section{$\underline{\text { Hematologic Malignancies }}$}

While the concept of cancer stage has traditionally not been applied in acute leukemia, the extent of CNS involvement has been shown to have clear prognostic importance, particularly in acute lymphoblastic leukemia (ALL) ${ }^{30,31}$ Thus, standard classifications of CNS involvement are endorsed for both ALL and acute myeloid leukemia (AML). Prognostic information unrelated to the extent of disease, such as white blood cell count and immunophenotype, are critical for patient management, but fall outside the scope of this paper. No staging system is endorsed for chronic myeloid leukemia (CML). The Ann Arbor staging system is well accepted in both paediatric and adult Hodgkin lymphoma (HL) and is therefore recommended. ${ }^{32}$ However, while Ann Arbor staging is also commonly used in adults with non-Hodgkin lymphoma (NHL), its utility in paediatric NHL is more limited as it is unable to adequately describe the extent of extranodal involvement. ${ }^{33}$ In the most common paediatric NHLs (e.g. Burkitt lymphoma, anaplastic large cell lymphoma), extra-nodal disease is common, with only CNS and/or bone marrow involvement having significant prognostic impact. ${ }^{34}$ The Ann Arbor staging system does therefore not allow the proper stratified comparison of outcomes between groups (principle 2). Similarly, the more recent Lugano Classification was also not endorsed due to its focus on adult lymphomas. ${ }^{35}$ The St. Jude/Murphy system, which records the extent of extra-nodal involvement, is generally preferred in paediatric NHL and was thus endorsed instead. ${ }^{36}$ 
Recently, a new International Pediatric Non-Hodgkin Lymphoma Staging System (IPNHLSS) has been proposed, building upon the St. Jude/Murphy system. ${ }^{37}$ As the IPNHLSS is not used in current paediatric protocols and awaits prospective validation, it was not incorporated into our recommendations. As staging systems evolve over time, future iterations of these recommendations may well include the IPNHLSS.

\section{$\underline{\text { Solid Tumours }}$}

In general, for solid tumours, a simplified classification describing extent of disease (e.g. localized, regional or metastatic) should be used for Tier 1 staging systems (Table 3). For neuroblastoma, The International Neuroblastoma Risk Group Staging (INRGSS) system should be used for both tiers. ${ }^{38}$ The INRGSS was developed to be able to compare pre-operative extent of disease independent of surgical skill and availability in order to overcome this specific criticism of the predecessor staging system, the International Neuroblastoma Staging System (INSS). ${ }^{38}$ The INRGSS recognizes that "resectability" in part reflects extent of disease but is also determined by the location and invasion of the tumour. These features, such as aorta encasement or tracheal compression, can be determined by pre-operative imaging (image-defined risk factors). An INRGSS L1 tumour is defined as localized tumour not involving a vital structure as defined by the list of image-defined risk factors and confined to one compartment. INRGSS L2 tumours are defined as locoregional tumour with presence of one of more image-defined risk factors. Although low resourced settings may not be able to obtain cross-sectional imaging that would allow evaluation of all of the image-defined risk factors, nonetheless clinicians usually decide, based on the data available, whether the patient is L1 or L2. The "MS" 
stage of INRGSS staging is analagous to the stage IV-S of the INSS system in which children less than 18 months of age with metastases confined to skin, liver and bone marrow have an excellent prognosis and are classified separately to prevent overtreatment. In contrast, children less than 18 months of age with bone metastases are classified as stage M (or stage IV disease in the INSS system), and have a worse prognosis that merits more intensive therapy.

For Wilms tumour, two principal staging systems exist. The COG/National Wilms Tumor Study Group (NWTSG) staging system is based on post-operative, pre-chemotherapy pathologic features and findings; the SIOP stage is based on the findings at surgery after the patient has received neo-adjuvant chemotherapy. ${ }^{17}$ This practice pattern is unlikely to change. For this malignancy, therefore, the use of the TNM prefix " $y$ " should be adopted for staging of the abdominal tumour. The prefix " $y$ " denotes the fact that stage was determined after neo-adjuvant chemotherapy was given: for example, a y-Stage II would be equivalent to a SIOP Stage II. Both groups recognize the presence of metastatic (stage IV) disease at diagnosis, based on imaging findings. Efforts encouraging institutions and cooperative trial groups to collect data based on pre-operative imaging regardless of what staging system was used to determine treatment would be welcome, but were beyond the scope of the panel.

In rhabdomyosarcoma, several factors determine treatment. ${ }^{39}$ The first are the classic components of TNM staging: the size of the tumour (less or more than $5 \mathrm{~cm}$ ), the presence of nodal metastases and metastatic disease. In addition however, some anatomic sites have a more favorable prognosis than others. The panel noted that tumour site is already routinely recorded in cancer registries as part of ICD-O coding, thus obviating the 
need to explicitly incorporate favorable vs. unfavorable site into registry staging systems. Likewise, histology (embryonal vs. alveolar) is also prognostic, but is also routinely collected as part of registry procedures. Finally, "clinical group", describing the extent of resection, is also used to determine treatment. Given the dependence on the availability and skill of the surgeon, the collection of "group" for rhabdomyosarcoma is not recommended for general registry purposes. In bone tumours, only 2 stages are recognized (localized or metastatic) for both Tier 1 and Tier 2 systems.

Of note, among many patients with solid tumours, site of metastasis may offer additional information on risk, with non-lung metastases (e.g. bone, bone marrow) portending worse outcomes than lung metastases. While the panel felt that site of metastasis represented a level of detail whose collection was beyond the capabilities of most population-based cancer registries, this variable could ideally be collected by highly resourced registries as part of a "Tier 3" system.

For retinoblastoma, the key prognostic criteria is whether the disease remains localized within the eye, has spread regionally (orbital or regional lymph nodes), or has spread to metastatic sites. The International Retinoblastoma Staging Systems (IRSS) captures this progression in extent of disease by including a stage 0 in which enucleation has not been required and ocular preservation treatments are applied. However, in HICs, the disease is typically detected at an early stage and hence treatment success is measured in terms of salvage of the eye itself, or the globe. Grouping systems have been developed that assess the extent of intraocular disease and thus the likelihood of eye salvage, beginning with the Reese-Ellsworth system in the 1950s. Intraocular group may be considered as an additional variable to be collected by registries with sufficient resources. ${ }^{40}$ 
For liver tumors, in resource-limited settings, the classification of the tumor as either localized or metastatic is sufficient. Liver tumours in HICs are increasingly staged using SIOP pre-treatment systems (PRETEXT) based on the number of liver segments involved. ${ }^{41}$. PRETEXT staging also includes a designation of "E" for extrahepatic disease, which is synonymous with regional extension of the tumour and a designation for involvement of the portal "P" and/or hepatic "H" veins. However, there is much interobserver variability in PRETEXT assignations when local institutional assignments have been compared to central expert review. Therefore, the collection of PRETEXT may be considered as a Tier 3 variable, but the presence or absence of metastatic disease would be sufficient in both Tiers 1 and 2 .

The most common tumours of the testes and ovary in paediatrics are germ cell tumours. As testicular tumours are most prevalent in young adults, the standard method of assigning stage, the TNM criteria, should be used..$^{42}$ For patients with disease that has spread beyond the testicle to the nodes or more distant metastatic sites, the International Germ Cell Consensus Classification (IGCCC) is used to assign risk group and recommend therapy ${ }^{43}$ The IGCCC incorporates the levels of post-operative tumour markers into the classification. In highly resourced settings, registries could therefore consider the collection of both site of metastatic disease and post-operative tumour marker levels as important non-stage prognostic variables.

For ovarian germ cell tumours, which occur mostly in older adolescents and young adults, the most common staging system used is the FIGO classification. ${ }^{44}$ The FIGO system was developed primarily for epithelial ovarian cancer and may not be completely 
relevant for ovarian germ cell tumours, but in order to be consistent with the data collected in adult women, recording FIGO stage is recommended.

\section{Central Nervous System Tumours}

Astrocytic tumours, medulloblastoma and ependymoma account for approximately $80 \%$ of all paediatric CNS tumours. Extent of disease is a significant prognostic factor in determining the intensity of therapy and predicting the outcome for many CNS malignancies, including medulloblastoma, other embryonal CNS tumours [pineoblastoma, primitive neuroectodermal tumour (PNET), atypical teratoid rhabdoid tumour (ATRT)], and ependymomas. ${ }^{45}$ Extent of disease is categorized according to the M-stage. In the absence of visible disease on imaging (MRI brain and spine) and absence of malignant cells in the cerebrospinal fluid (CSF), M0 applies. M1 codes positive tumour cells in the CSF, M2 visible metastases in brain, M3 visible metastases in spine and M4 metastases outside of the CNS. ${ }^{11}$

Significant prognosticators in childhood astrocytomas include histology, WHO grade, and site of disease. Astrocytomas are unlikely to spread beyond their initial site; examination of the CSF is not considered necessary in the initial workup. The working group therefore endorses no staging system for these malignancies.

While extent of surgical resection in CNS tumors has critical prognostic impact, it does not reflect anatomic extent of disease and should therefore be considered a non-stage prognosticator. Extent of resection is classified as no resection (including biopsy) versus subtotal versus gross total resection for astrocytic tumours and ependymomas. In 
medulloblastoma the extent of resection is presently classified according to the amount of residual disease. ${ }^{46,47}$

\section{BARRIERS TO ADOPTION}

There are several barriers to the widespread adoption of these staging recommendations by population-based cancer registries. Childhood cancer represents a small percentage of the overall cancer burden in a population; ${ }^{10,48}$ general population-based cancer registries focus their efforts on collecting data on major neoplasms that occur in adults and may not have sufficient time and energy to refine classifications aimed at this small subpopulation. Advocacy efforts on the part of childhood cancer organizations may be needed to overcome this barrier.

Additionally, as referenced several times above, many registries face limited and even decreasing funding levels; ${ }^{6}$ thus, to capture any additional data elements will require increased resources. Registries initiating the capture of paediatric cancer stage should also identify the level of additional funding required to do so in order to better inform health policymakers and researchers in other jurisdictions. Studies using stage data (e.g. outcome comparisons between groups or over time, trends in disease extent at presentation) will also help demonstrate the utility of collection of these data to advocates, policymakers and clinicians. Here, the relative rarity of childhood cancer may be an advantage; a small outlay of additional funds to collect stage in paediatric patients followed by demonstrating the feasibility and value of stage data will help advocate for similar efforts in adult populations. 
For registries that already collect paediatric stage, there may be resistance to changing current practice and implementing the Toronto Paediatric Cancer Stage Guidelines. This may be particularly difficult in countries without a national registry but with multiple subnational registries. However the benefits of a uniform system that can be used by registry staff using available records and that will allow consistent reporting and international comparisons are considerable.

Finally, registries are limited by what data are available in medical records. Additional efforts are required to ensure that clinicians clearly and consistently document cancer stage in sources accessible to cancer registrars.

\section{LIMITATIONS}

We used a modified-Delphi approach to achieve our objectives. A limitation of this approach is its dependence on the composition of the participant group; "homogeneity in Consensus Group composition is likely to result in homogeneity of ratings". ${ }^{13}$ Homogeneity also increases the likelihood of specific biases affecting the recommendations. We addressed these limitations by ensuring a wide range of viewpoints in the consensus group, including both clinicians and epidemiologists, LMIC and HIC panelists, geographic diversity, experts in paediatric and adult cancer staging, individuals with experience of leading cancer registries, and representatives of major international stakeholder organizations. This heterogeneity of backgrounds lends credibility to the recommendations endorsed by group consensus. Lending further credibility, the Toronto Paediatric Cancer Stage Guidelines have subsequently been endorsed by the UICC TNM Prognostic Factors Project. 


\section{FUTURE STEPS}

The tiered, paediatric-specific staging systems endorsed by the panel and presented in this paper should be adopted for use by population-based cancer registries and integrated into registry manuals. To facilitate this, coding guidelines will be disseminated through various platforms, including through various stakeholder organisations. Pilot investigations determining how the methods used to record stage influence the quality of the data and the resources required to collect valid paediatric stage data across various resource settings will help inform policymakers. Such pilot studies are already underway in Australia and several Central American jurisdictions. The results of the pilots, implementation experience from other registries, and future changes in treatment and progress will likely require future modifications to these endorsements, an iterative process characteristic of all staging systems. Finally, comparative studies across jurisdictions and time will help demonstrate the value of population-based stage data.

\section{CONCLUSIONS}

Stage is an essential indicator of cancer prognosis, and as such warrants collection by population-based cancer registries. As most paediatric cancers have specific staging systems, general adult stage classifications are not appropriate. We recommend that the tiered, paediatric-specific staging systems endorsed in this paper as the Toronto Paediatric Cancer Stage Guidelines be adopted for paediatric cases by cancer registries in both LMICs and HICs. 


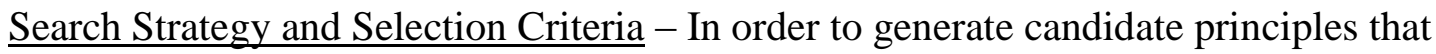
would guide the collection of childhood cancer stage by population-based cancer registries, Ovid Medline was searched using the following terms: "exp Neoplasms/" AND “exp Registries/” AND exp "Neoplasm Staging/" AND “exp Child/”. The search was limited to articles in English and published from 1990 updated to the end of 2014. The 236 identified articles pertained to specific cohorts with particular malignancies and not candidate principles.

Contributors - SG and LF conceived of the study idea and design. SG undertook the analyses. All authors were involved in the data interpretation and critical revisions of the report, and approved the final version. SG is the guarantor of the report, had full access to all the data and had final responsibility for the decision to submit for publication.

Declaration of Interests - Dr. Steliarova-Foucher reports a travel grant from the Union for the International Control of Cancer (UICC), and Ms. Ries reports funding from the National Cancer Institute (NCI) during the conduct of the study. All other authors declare no conflicts of interest.

Acknowledgments - The in-person meeting held for all panelists in Toronto, Canada on October $19^{\text {th }}, 2014$ was supported by the Center for Global Health of the National Cancer Institute (NCI). In-kind funding and support was provided by the Hospital for Sick Children. Funding sources had no role in study design; in the collection, analysis, and interpretation of data; in the writing of the report; and in the decision to submit for 
publication.

We acknowledge the insights provided by Dr. Andrew Hallahan, Prof. Adèle Green, Prof.

Peter Baade, Mr. Danny Youlden, Dr. Patricia Valery, and Ms. Leisa Ward. We also

acknowledge the help of Ms. Rosanna Yankanah and Ms. Tiffany Jiminez, as well as the encouragement of Dr. James Whitlock. 
Table 1: Characteristics of panelists $(\mathrm{N}=28)$

\begin{tabular}{|l|c|}
\hline & $\mathbf{N}(\%)$ \\
\hline Gender & \\
\hline Male & $12(42 \cdot 9)$ \\
\hline Female & $16(57 \cdot 1)$ \\
\hline Geographic area & \\
\hline Canada/USA & $12(42 \cdot 9)$ \\
\hline Europe & $5(17 \cdot 9)$ \\
\hline Asia & $5(17 \cdot 9)$ \\
\hline Latin America & $4(14 \cdot 3)$ \\
\hline Africa & $1(3 \cdot 6)$ \\
\hline Oceania & $1(3 \cdot 6)$ \\
\hline Resource setting* & \\
\hline HIC & $18(64 \cdot 3)$ \\
\hline LMIC & $10(35 \cdot 7)$ \\
\hline Area of expertise** & \\
\hline Clinical paediatric oncology & $20(71 \cdot 4)$ \\
\hline Epidemiology & $14(50 \cdot 0)$ \\
\hline Cancer registration & $15(53 \cdot 6)$ \\
\hline
\end{tabular}

HIC - high-income country; LMIC - low- or middle-income country; USA - United States of America *Based on World Bank definitions of HIC and $\mathrm{LMIC}^{49}$

**Figures do not add to $100 \%$ as individuals could have more than one area of expertise 
Table 2. The Toronto Paediatric Cancer Stage Guidelines - Guiding principles of the collection of stage of childhood malignancies in population-based registries

\begin{tabular}{|l|}
\hline Rationale for Collection \\
\hline 1. Cancer registries should routinely collect disease stage data for cases of paediatric cancer. \\
\hline $\begin{array}{l}\text { 2. A primary reason for collecting disease stage in cancer registries is to allow stratified comparison of } \\
\text { outcomes between groups or over time. }\end{array}$ \\
\hline $\begin{array}{l}\text { 3. A primary reason for collecting disease stage in cancer registries is to identify trends in late } \\
\text { presentation through the proxy of advanced stage at diagnosis, though this may not be applicable to all } \\
\text { childhood cancers or all jurisdictions. }\end{array}$ \\
\hline Relationship to Adult Cancer Staging \\
\hline 4. Cancer registries should routinely use paediatric specific staging systems for childhood cancer cases. \\
\hline $\begin{array}{l}\text { 5. For malignancies common across both paediatric and adult age groups (e.g. Hodgkin lymphoma, } \\
\text { testicular cancer), staging systems should be the same. }\end{array}$ \\
\hline $\begin{array}{l}\text { 6. TNM based staging systems used in adult patients are of limited use for many, but not all paediatric } \\
\text { malignancies }\end{array}$ \\
\hline Specificities of Paediatric Staging Systems \\
\hline 7. Stage should reflect the extent of disease. \\
\hline 8. Staging systems used in paediatric cancer registries should be as simple yet informative as possible. \\
\hline $\begin{array}{l}\text { 9. Registries should collect stage for paediatric cancer according to internationally endorsed } \\
\text { classification systems. }\end{array}$ \\
\hline $\begin{array}{l}\text { 10. When staging paediatric malignancies, clinical staging (i.e. staging at the time of diagnosis) is } \\
\text { important and often should be collected. }\end{array}$ \\
\hline $\begin{array}{l}\text { 11. The importance of pathologic staging (i.e. staging at the time of surgery/resection), and the staging } \\
\text { system by which it should be collected, will vary between paediatric malignancies. }\end{array}$ \\
\hline Adaptation for Resource-Limited Settings \\
\hline $\begin{array}{l}\text { 12. "Tiered"-staging staging systems should be endorsed, with more detailed systems for well-resourced } \\
\text { cancer registries with appropriate data access, and less detailed systems for registries with more limited } \\
\text { resources and access. Lower-tier systems should be based on collapsing higher-tier system categories in } \\
\text { order to preserve a degree of comparability across registries. }\end{array}$ \\
\hline
\end{tabular}


Table 3. The Toronto Paediatric Cancer Stage Guidelines - Tiered staging systems for the main childhood cancers

\begin{tabular}{|c|c|c|c|}
\hline Malignancy & Tier 1 Staging System & Tier 2 Staging System & Comments \\
\hline \multirow{3}{*}{ ALL } & CNS negative & CNS $1^{30}$ & 1. Collection of testicular involvement not endorsed given rarity and \\
\hline & \multirow{2}{*}{ CNS positive } & CNS 2 & uncertain prognostic value in first presentation disease \\
\hline & & CNS 3 & 2. White blood cell count at presentation not felt reflective of stage \\
\hline \multirow{2}{*}{ AML } & CNS negative & CNS negative $^{31}$ & \multirow[b]{2}{*}{-} \\
\hline & CNS positive & CNS positive & \\
\hline CML & None & None & 1. No relevant staging system identified or necessary \\
\hline HL & \multicolumn{2}{|c|}{$\begin{array}{l}\text { Ann Arbor - Stage IA/B }{ }^{32} \\
\text { Ann Arbor }- \text { Stage IIA/B } \\
\text { Ann Arbor - Stage IIIA/B } \\
\text { Ann Arbor - Stage IVA/B }\end{array}$} & $\begin{array}{l}\text { 1. Used in both adult and paediatric populations } \\
\text { 2. Recent proposals in adult populations to move to more simplified } \\
\text { "limited" vs. "advanced" staging classifications }{ }^{50} \text { not yet evaluated in } \\
\text { paediatric populations } \\
\text { 3. Multi-tiered staging systems not felt appropriate } \\
\text { 4. See Discussion for utility of collecting modalities used in staging workup }\end{array}$ \\
\hline \multirow{4}{*}{ NHL } & \multirow{3}{*}{ Limited } & $\begin{array}{l}\text { St. Jude/Murphy - Stage } \\
\text { I }^{36}\end{array}$ & \multirow{4}{*}{$\begin{array}{l}\text { 1. Tier } 1 \text { "Advanced" stage reflects CNS and/or bone marrow involvement } \\
\text { 2. Though some clinicians will use Ann Arbor staging for NHL, St. } \\
\text { Jude/Murphy more often used in paediatric populations. Ann Arbor Stage IV } \\
\text { will often, but not always, correspond to Tier } 1 \text { "Advanced" stage disease } \\
\text { 3. Whether Ann Arbor or St. Jude/Murphy staging systems were used by } \\
\text { clinicians may be difficult to ascertain from medical charts }\end{array}$} \\
\hline & & St. Jude/Murphy - Stage II & \\
\hline & & $\begin{array}{l}\text { St. Jude/Murphy - Stage } \\
\text { III }\end{array}$ & \\
\hline & Advanced & $\begin{array}{c}\text { St. Jude/Murphy - Stage } \\
\text { IV }\end{array}$ & \\
\hline \multirow{4}{*}{ Neuroblastoma } & Localized & INRGSS - Localized L1 ${ }^{38}$ & \multirow{4}{*}{$\begin{array}{l}\text { 1. MS disease refers to children younger than } 18 \text { months with metastases } \\
\text { confined to skin, liver, and/or bone marrow } \\
\text { 2. The first two stages of the Tier } 1 \text { system are intended to be simplified } \\
\text { proxies of INRGSS L1 and L } 2 \text { not dependent on adequate assessment of } \\
\text { imaging-defined risk factors. They will not however correlate perfectly. }\end{array}$} \\
\hline & Locoregional & $\begin{array}{c}\text { INRGSS - Locoregional } \\
\text { L2 }\end{array}$ & \\
\hline & Metastatic & INRGSS - Metastatic M & \\
\hline & INRGSS - MS Disease & INRGSS - MS Disease & \\
\hline \multirow{5}{*}{ Wilms tumour } & \multirow{3}{*}{ Localized } & Stage $\mathrm{I}^{17} / \mathrm{y}$-Stage $\mathrm{I}^{17}$ & \multirow{4}{*}{$\begin{array}{l}\text { 1. In keeping with current staging conventions, the "y" designates that } \\
\text { staging assessment was performed after neo-adjuvant therapy was given. } \\
\text { This allows the staging system to accommodate both SIOP and } \\
\text { COG/NWTSG based treatment strategies }{ }^{17} \\
\text { 2. In cases of bilateral disease the stage of the most advanced kidney should } \\
\text { be recorded. }\end{array}$} \\
\hline & & Stage II / y-Stage II & \\
\hline & & Stage III / y-Stage III & \\
\hline & Metastatic & Stage IV & \\
\hline & Localized & TNM Stage $1^{29}$ & \\
\hline
\end{tabular}




\begin{tabular}{|c|c|c|c|}
\hline \multirow{3}{*}{$\begin{array}{c}\text { Rhabdomyosarc } \\
\text { oma }\end{array}$} & \multirow[b]{3}{*}{ Metastatic } & TNM Stage 2 & \multirow{3}{*}{$\begin{array}{l}\text { 1. RMS overall stage incorporates both TNM staging and site of disease. As } \\
\text { registries collect primary disease site, overall RMS stage may be } \\
\text { approximated with either tier staging system endorsed here. } \\
\text { 2. For very highly resourced registries, a "Tier 3" system incorporating site } \\
\text { of metastases may be considered }\end{array}$} \\
\hline & & TNM Stage 3 & \\
\hline & & TNM Stage 4 & \\
\hline \multirow{4}{*}{$\begin{array}{c}\text { Non- } \\
\text { rhabdomyosarc } \\
\text { oma soft tissue } \\
\text { sarcomas }\end{array}$} & \multirow{3}{*}{ Localized } & TNM Stage $1^{29}$ & \multirow{4}{*}{ - } \\
\hline & & TNM Stage 2 & \\
\hline & & TNM Stage 3 & \\
\hline & Metastatic & TNM Stage 4 & \\
\hline Osteosarcoma & \multicolumn{2}{|c|}{$\begin{array}{l}\text { Localized } \\
\text { Metastatic }\end{array}$} & $\begin{array}{l}\text { 1. While more detailed staging systems exist, }{ }^{51} \text { their clinical and prognostic } \\
\text { value is limited } \\
\text { 2. Multi-tiered staging systems were not felt appropriate } \\
\text { 3. For very highly resourced registries, a "Tier 3" system incorporating site } \\
\text { of metastases may be considered }\end{array}$ \\
\hline Ewing sarcoma & \multicolumn{2}{|c|}{$\begin{array}{l}\text { Localized } \\
\text { Metastatic }\end{array}$} & $\begin{array}{l}\text { 1. While more detailed staging systems exist, }{ }^{51} \text { their clinical and prognostic } \\
\text { value is limited } \\
\text { 2. Multi-tiered staging systems were not felt appropriate } \\
\text { 3. For very highly resourced registries, a "Tier 3" system incorporating site } \\
\text { of metastases may be considered. }\end{array}$ \\
\hline \multirow{5}{*}{ Retinoblastoma } & \multirow{3}{*}{ Localized (intraocular) } & IRSS Stage $0^{40}$ & \multirow{5}{*}{$\begin{array}{l}\text { 1. In keeping with current registry guidelines for retinoblastoma, in cases of } \\
\text { bilateral disease the stage of the most advanced eye should be recorded } \\
\text { 2. Within IRSS Stage 0, Group A-E was considered Tier } 3 \text { recommendation }\end{array}$} \\
\hline & & IRSS Stage I & \\
\hline & & IRSS Stage II & \\
\hline & $\begin{array}{l}\text { Regional (orbital and/or } \\
\text { regional lymph nodes) }\end{array}$ & IRSS Stage III & \\
\hline & Distant (extra-orbital) & IRSS Stage IV & \\
\hline \multirow{2}{*}{ Hepatoblastoma } & \multicolumn{2}{|c|}{ Localized } & \multirow{2}{*}{ 1. Collection of PRETEXT is a Tier 3 option. ${ }^{41}$} \\
\hline & \multicolumn{2}{|c|}{ Metastatic } & \\
\hline \multirow{4}{*}{ Testicular } & Localized & TNM Stage I ${ }^{42}$ & \multirow{4}{*}{$\begin{array}{l}\text { 1. Though the Tier } 1 \text { and Tier } 2 \text { staging systems are perfect correlates, the } \\
\text { individual components of TNM staging would not be collected in the Tier } 1 \\
\text { system. }\end{array}$} \\
\hline & Regional & TNM Stage II & \\
\hline & & & \\
\hline & Metastatic & TNM Stage III & \\
\hline
\end{tabular}




\begin{tabular}{|c|c|c|c|}
\hline \multirow{4}{*}{ Ovarian } & Localized & FIGO Stage I ${ }^{44}$ & \multirow{4}{*}{ - } \\
\hline & \multirow{2}{*}{ Regional } & FIGO Stage II & \\
\hline & & FIGO Stage III & \\
\hline & Metastatic & FIGO Stage IV & \\
\hline Astrocytomas & None & None & 1. No relevant staging system identified or necessary \\
\hline \multirow{5}{*}{$\begin{array}{l}\text { Medulloblasto } \\
\text { ma and other } \\
\text { CNS embryonal } \\
\text { tumours }\end{array}$} & M0/Localized & $\mathrm{M}^{11}$ & \multirow{5}{*}{$\begin{array}{l}\text { 1. Residual disease, defined as }>1.5 \mathrm{~cm}^{2} \text { after resection, is an important non- } \\
\text { stage prognosticator and may be considered for collection by appropriately } \\
\text { resourced registries }\end{array}$} \\
\hline & \multirow{4}{*}{ M+/Metastatic } & M1 & \\
\hline & & M2 & \\
\hline & & M3 & \\
\hline & & M4 & \\
\hline \multirow{5}{*}{ Ependymoma } & M0 & M0 & \multirow{5}{*}{$\begin{array}{l}\text { 1. Extent of resection, defined as no resection vs. subtotal vs. gross total, is } \\
\text { an important non-stage prognosticator and may be considered for collection } \\
\text { by appropriately resourced registries }\end{array}$} \\
\hline & \multirow{4}{*}{ M+ } & M1 & \\
\hline & & M2 & \\
\hline & & M3 & \\
\hline & & M4 & \\
\hline
\end{tabular}

AJCC - American Joint Committee on Cancer; ALL - acute lymphoblastic leukemia; AML - acute myeloid leukemia; CML - chronic myeloid leukemia; CNS - central nervous system; COG Children's Oncology Group; FIGO - International Federation of Gynaecological Oncologists; HL - Hodgkin lymphoma; INRGSS - International Neuroblastoma Risk Group Staging System; IRSS International Retinoblastoma Staging System; MB - Medulloblastoma; NHL - non-Hodgkin lymphoma; NWTSG - National Wilms Tumour Study Group; RMS - rhabdomyosarcoma; SIOP International Society of Paediatric Oncology 


\section{REFERENCES}

1. Hershman DL, Wright JD. Comparative effectiveness research in oncology methodology: Observationa data. J Clin Oncol 2012; 30(24): 4215-22.

2. Gatta G, Capocaccia R, Stiller C, et al. Childhood cancer survival trends in Europe: A EUROCARE Working Group study. J Clin Oncol 2005; 23: 3742-51.

3. Smith BD, Smith GL, Hurria A, Hortobagyl GN, Buchholz TA. Future of cancer incidence in the United States: Burdens upon an aging, changing nation. J Clin Oncol 2009; 27: 2758-65.

4. $\quad$ Smith MA, Seibel NL, Altekruse SF, et al. Outcomes for children and adolescents with cancer: Challenges for the twenty-first century. J Clin Oncol 2010; 28: 2625-34.

5. Gatta G, Botta L, Rossi S, et al. Childhood cancer survival in Europe 19992007: results of EUROCARE-5 - A population-based study. Lancet Oncol 2014; 15: 35-47.

6. Ferlay J, Steliarova-Foucher E, Lortet-Tieulent J, et al. Cancer incidence and mortality patterns in Europe: Estimates for 40 countries in 2012. Eur J Cancer 2013; 49: 1374-403.

7. Bray F, Ren JS, Masuyer E, Ferlay J. Global estimates of cancer prevalence for 27 sites in the adult population in 2008. Int J Cancer 2013; 132: 1133-45.

8. Webber C, Gospodarowicz M, Sobin LH, et al. Improving the TNM classification: Findings from a 10-year continuous literature review. Int J Cancer 2014; 135: 371-8.

9. Chawla N, Yabroff KR, Mariotto AB, McNeel TS, Schrag D, Warren JL. Limited validity of diagnosis codes in Medicare claims for identifying cancer metastases and inferring stage. Ann Epidemiol 2014; 24: 666-72.

10. Ward E, DeSantis C, Robbins A, Kohler B, Jemal A. Childhood and adolescent cancer statistics, 2014. CA Cancer J Clin 2014; 64: 83-103.

11. Harisiadis L, Chang $\mathrm{CH}$. Medulloblastoma in children: a correlation between staging and results of treatment. Int J Radiat Oncolg Biol Phys 1977; 2: 833-41.

12. Jones J, Hunter D. Consensus methods for medical and health services research. $B M J$ 1995; 311: 376-80.

13. Loblaw DA, Prestrud AA, Somerfield MR, et al. American Society of Clinical Oncology Clinical Practice Guidelines: Formal Systematic Review-Based Consensus Methodology. J Clin Oncol 2012; 30: 3136-40.

14. Leander C, Fu L, Pena A, et al. Impact of an education program on late diagnosis of retinoblastoma in Honduras. Pediatr Blood Cancer 2007; 49: 817-9.

15. Smith EC, Ziogas A, Anton-Culver H. Association between insurance and socioeconomic status and risk of advanced stage Hodgkin lymphoma in adolescents and young adults. Cancer 2012; 118: 6179-87.

16. Esiashvili N, Goodman M, Ward K, Marcus RBJ, Johnstone PA. Neuroblastoma in adults: Incidence and survival analysis based on SEER data. Pediatr Blood Cancer 2007; 49: 41-6.

17. Metzger ML, Dome JS. Current therapy for Wilms' tumor. The Oncologist 2005; 10: 815-26. 
18. Brierley J, Greene FL, Sobin LH, Wittekind C. The "y" symbol: an important classification tool for neoadjuvant cancer treatment. Cancer 2006; 106(11): 2526-7. 19. Ferlay J, Shin H-R, Bray F, Forman D, Mathers C, Parkin DM. Estimates of worldwide burden of cancer in 2008: GLOBOCAN 2008. Int J Cancer 2010; 127: 2893-917.

20. Marrett L, Clarke A, Hatcher J, Weir H. Epidemioogic research using the Ontario Cancer Registry. Can J Public Health 1986; 77: 79-85.

21. Greenberg ML, Barr RD, DiMonte B, McLaughlin E, Greenberg C. Childhood cancer registries in Ontario, Canada: Lessons learned from a comparison of two registries. Int J Cancer 2003; 105: 88-91.

22. Gupta S, Pole JD, Guttmann A, Sung L. Validation of a registry-derived risk algorithm based on treatment protocol as a proxy for disease risk in childhood acute lymphoblstic leukemia. BMC Med Res Method 2013; 13(68).

23. Youlden DR, Baade PD, Valery PC, Ward LJ, Green AC, Aitken JF. Differentials in survival for childhood cancer in Australia by remoteness of residence and area disadvantage. Cancer Epidemiol Biomarkers Prev 2011; 20: 1649-56.

24. Parkin DM, Bray F. Evaluation of data quality in the cancer registry: Principles and Methods. Part II. Completeness. Eur J Cancer 2009; 45: 756-64.

25. Parkin DM, Bray F. Evaluation of data quality in the cancer registry: Principles and methods. Part I: Comparability, validity and timeliness. Eur J Cancer 2009; 45: 747-55.

26. Hesseling P, Israels T, Harif M, Chantada G, Molyneux E. Practical recommendations for the management of children with Endemic Burkitt Lymphoma (BL) in a resource limited setting. Pediatr Blood Cancer 2013; 60(3): 357-62.

27. El-Galaly TC, d'Amore F, Mylam KJ, et al. Routine bone marrow biopsy has little or no therapeutic conxequence for positron emission tomography/computed tomography-staged treatment-naive patients with Hodgkin lymphoma. J Clin Oncol 2012; 30: 4508-14.

28. Perkins SM, Shinohara ET, DeWees T, Frangoul H. Outcome for children with metastatic solid tumors over the last four decades. PLoS One 2014; 9: e100396.

29. Union for International Cancer Control. TNM Classification of Malignant Tumours, 7th edition: Wiley; 2009.

30. Pui CH. Central nervous system disease in acute lymphoblastic leukemia: prophylaxis and treatment. Hematology Am Soc Hematol Educ Program 2006; (1426).

31. Abbott BL, Rubnitz JE, Tong X, et al. Clinical significance of central nervous system involvement at diagnosis of pediatric acute myeloid leukemia: a single institution experience. Leukemia 2003; 17: 2090-6.

32. Carbone PP, Kaplan HS, Musshoff K, Smithers DW, Tubiana M. Report of the Committee on Hodgkin's Disease Staging Classification. Cancer Res 1971; 31: 18601.

33. Blum KA, Lozanski G, Byrd JC. Adult Burkitt leukemia and lymphma. Blood 2004; 104: 309-20.

34. Cairo MS, Sposto R, Gerrard M, et al. Advanced stage, increased lactate dehydrogenase, and primary site, but not adolescent age ( $>15$ years), are associated with an increased risk of treatment failure in children and adolescents with mature 
B-cell non-Hodgkin's lymphoma: Results of the FAB LMB 96 Study. J Clin Oncol 2012; 30(4).

35. Cheson BD, Fisher RI, Barrington SF, et al. Recommendations for initial evaluation, staging and response assessment of Hodgkin and non-Hodgkin lymphoma: The Lugano Classificaiton. J Clin Oncol 2014; 32(27): 3059-67.

36. Murphy SB. Classification, staging and end results of treatment of childhood non-Hodgkin's lymphomas: Dissimilarities from lymphomas in adults. Semin Oncol 1980; 7: 332-9.

37. Rosolen A, Perkins SL, Pinkerton C, et al. Revised International Pediatric NonHodgkin Lymphoma Staging System. J Clin Oncol 2015; 33(18): 2112-8.

38. Monclair T, Brodeur GM, Ambros PF, et al. The International Neuroblastom

Risk Group (INRG) Staging System: An INRG Tast Force report. J Clin Oncol 2009; 27: 298-303.

39. Weiss AR, Lyden ER, Anderson JR, et al. Histologic and clinical characteristics can guide staging evaluations for children and adolescents with rhabdomyosarcoma: a report from the Children's Oncolgy Group Soft TIssue Sarcoma Committee. J Clin Oncol 2013; 31(26): 3226-32.

40. Chantada G, Doz F, Antonelli CB, et al. A proposal for an international retinoblastoma staging system. Pediatr Blood Cancer 2006; 47: 801-5.

41. Roebuck DJ, Aronson D, Clapuyt P, et al. 2005 PRETEXT: a revised staging system for primary malignant liver tumours of childhood developed by the SIOPEL group. Pediatr Radiol 2007; 37(2): 123-32.

42. American Joint Committee on Cancer. AJCC Cancer Staging Manual. 7th ed: Springer Scient and Business Media, LLC (SBM); 2010.

43. International Germ Cell Consensus Classification: a prognostic factor-based staging system for metastatic germ cell cancers. International Germ Cell Cancer Collaborative Group. Journal of clinical oncology : official journal of the American Society of Clinical Oncology 1997; 15(2): 594-603.

44. Prat J. Staging classification for cancer of the ovary, fallopian tube, and peritoneum. Int J Gynecol Obstetrics 2014; 124(1): 1-5.

45. Louis DN, Ohgaki H, Wiestler OD, Cavenee WK. WHO Classification of Tumours of the Central Nervous System. Lyon: International Agency for Research on Cancer, 2007.

46. Zeltzer PM, Boyett JM, Finlay JL, et al. Metastasis stage, adjuvant treatment, and residual tumor are prognostic factors for medulloblastoma in children: Conclusions from the Children's Cancer Group 921 Randomized Phase III Study. J Clin Oncol 1999; 17(3): 832-45.

47. Rutkowski S, von Hoff K, Emser A, et al. Survival and prognostic factors of early childhood medulloblastoma: An international meta-analysis. J Clin Oncol 2010; 28(33): 4961-68.

48. Steliarova-Foucher E, Frazier L. Childhood cancer. Lyon: International Agency for Research on Cancer, 2014.

49. World Health Organisation. WHO Definition of region groupings. 2014. http://www.who.int/healthinfo/global burden disease/definition regions/en (accessed November 7th 2014). 
50. Chesson BD, Fisher RI, Barrington SF, et al. Recommendations for Initial Evaluation, Staging, and Response Assessment of Hodgkin and non-Hodgkin Lymphoma: The Lugano Classification. J Clin Oncol 2014; 32.

51. American Joint Committee on Cancer. Bone. AJCC Cancer Staging Manual. 7th edition ed. New York: Springer-verlag; 2010: 281-7. 